\title{
Causal factors contributing to participation in the elderly care of care-for-the-elderly-at-home volunteers in Thailand
}

\author{
Piyakorn Whangmahaporn \\ Associate Professor, Sripatum University \\ Bangkok, Thailand \\ tanyaw@gmail.com
}

\begin{abstract}
The main purpose of this research are (1) to examine the relationship between the motivation and satisfaction affects the participation in the elderly care (2) to facilitate

comparison of the participation in the elderly care and different factors of volunteers and (3) to investigate facing problems to

participation in the elderly care. This research is mixed methods using questionnaires and semi-structured interviews. The areas

for surveying are in six regions of twelve provinces in Thailand with 400 care-for-the-elderly-at-home-volunteers. The influences of

all variables in the casual model affected the volunteers' participation in elderly caring. The differences in age, occupation,

family size, frequency of attending training after becoming a volunteer, duration of work duty, subordination, and duty section of the volunteers have a statistical significance in a level of .00.0The main participation problems are an elderly's family fails to cooperate, there are not enough volunteers, and the budget is limited.
\end{abstract}

Keywords-causal factors, participation, elderly care, care -forthe-elderly-at-home volunteers,Thailand

\section{INTRODUCTION}

The raising amount of the elderly population in every country is considered to be one of the social problems in today's world. The estimated data during the year of 2010 to

2040 of the Thai population done by ONESDB shows that the ratio of the elderly population, especially in the age above 80 , tends to be significantly increased; in other word, the ratio of the late elderly population will be increased to 12.7 percent

from the overall elderly population, resulting in the increase of the dependent population in the country. In Thailand, the government sector is responsible for such social services. The result from the new concept of the government called "Governance" alters the government to modify its infrastructure and helps in decentralizing social services to local administrative organizations. Therefore, having a volunteer for caring the elderly in a local area is one of the ways to support in long-term caring of the elderly in such area and to serve as the main part in social services. Although such volunteers

serve as a crucial part in social services and a link between a government sector and the elderly in the local area, the findings from studies involving in the participation of such volunteers show that the participation in the elderly care of such volunteers is still in the mid-low rate. This study may contribute to the development of the new way to participate in caring the elderly. In addition, the findings on motivation and satisfaction of the volunteers may provide enough information to be used in aiding a task of the volunteers as well as keeping such task organized in order for the volunteers to be able in providing such care in long term with the best possible satisfaction.

\section{THE PURPOSE OF THE STUDY}

The purpose of this study were to study the casual factors contributing to the need for participating in caring the elderly of the volunteers and to compare the participation in the elderly care of care-for-the-elderly-at-home volunteers and

different factors of volunteers and to study the problems that may occur from such participation.

\section{III.}

\section{HYPOTHESIS}

Hypothesis 1: The motivation of becoming care-for-theelderly-at-home volunteers has a direct influence on the participation in volunteering administration of the volunteers.

Hypothesis 2: The motivation of becoming the volunteers has a direct influence on the satisfaction of such volunteers.

Hypothesis 3: The motivation of becoming one of the volunteers directly affects the volunteers' participation in volunteering administration through the satisfaction factors.

Hypothesis 4: The different factors such as gender, age,

occupation, monthly income, education level, marriage status, family size, other duties in social services, frequency of participating in training after becoming a volunteer, approach of becoming the volunteer, duration of working as the volunteer, subordination, reported agency of the individual, care-for-the-elderly-at-home volunteer could impact the different level of participation in the elderly care. 


\section{RESEARCH METHODOLOGY}

Mixed methods are used in this study. The population used for an quantitative research is care-for-the-elderly-at-home volunteers in the total number of 18,118 from six regions of Thailand in the total of twelve provinces. The sample size of 400 is determined at reliability of 5.0and multiple steps with simple random sampling. Questionnaires with a five-point scale are used in this study and have been examined for the content validity by calculating for the rate of Item Objective Congruence (IOC) and passed with IOC between 5.1 and 8.5, which is higher than the expected rate at .5.0. In addition, the reliability of the questionnaires is calculated by using Alpha Coefficient, and the result after calculated is 5.205, which is higher than the expected rate of reliability at 5.0

For the data analysis, descriptive statistics such as arithmetic mean and standard deviation, as well as inferential statistics such as the use of LISREL model are used. The

analysis of basic statistical value of variables used in the model consists of 15 observable variables is described in the values of frequency, mean, skewness, kurtosis, standard deviation, coefficient of variation, Pearson's product-moment

correlation coefficient, and construct validity using confirmatory factor analysis. One-way ANCOVA for calculating and facilitating comparison of the level of participation in the elderly care of care-for-the-elderly-at-home volunteers and individual factors, of which the motive of the volunteers is successfully controlled, the use of one-way

ANOVA in the case that the level of the motive of participating is not significant or does not directly impact the participation of the volunteers, and the use of LSD or Dunnett $\mathrm{T} 8$ for testing differences between means are applied

For a qualitative research, the key informants includes a care-for-the-elderly-at-home volunteer, local administrative organization representatives, social development and human security ministry agents, and village or sub-district headmen in twelve of each from the similar area as described. A screening process is done by using a semi-structure interview.

\section{RESULTS}

\section{A. Phrase I: The results from analyzing the hypothesized structural formula model}

The results from the model of the relationship between the motivation of becoming a volunteer (MOT), the volunteers' working satisfaction (SAT), and the volunteers' participation in caring designed by the researcher give the value of deviation that may be related to one another. The model has not been fit to the obvious data. The statistical values are $\chi^{2}=530.20, \mathrm{df}=87, \mathrm{p}$-value $=0.000, \mathrm{CFI}=0.99, \mathrm{GFI}=0.85, \mathrm{AGFI}=0.79, \mathrm{RMSEA}=0.113$, and $\mathrm{SRMR}=0.013$. Some of which are not considered to pass the set value; from this reason, model modification must be made with model modification indices (MI) in consideration to make an index fit to the obvious data as shown in Figure 1 and Table I

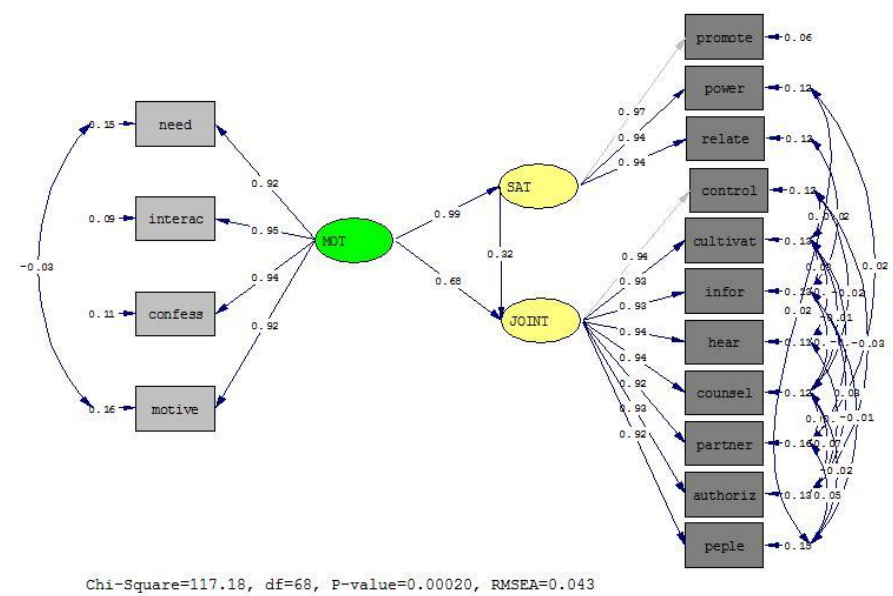

Fig. 1. Analyzing of the fit indexes of all models (after changing some deviation parameters)

TABLE I. ANALYZING OF THE FIT INDEXES OF THE MODELS

\begin{tabular}{cccc}
\hline Fit Indexes & Standard Value & Measured Value & $\begin{array}{c}\text { Indicatio } \\
\mathbf{n}\end{array}$ \\
\hline$\chi^{2} / \mathrm{df}(117.18 / 68)$ & $<2.00$ & 1.723 & Pass \\
CFI & $>0.95$ & 1.00 & Pass \\
GFI & $>0.95$ & 0.96 & Pass \\
AGFI & $>0.90$ & 0.93 & Pass \\
RMSEA & $<0.05$ & 0.043 & Pass \\
SRMR & $<0.05$ & 0.006 & Pass \\
\hline
\end{tabular}

From Table I, it is found that the models are fit with the obvious data with the pass fit indexes: $\chi^{2} \mathrm{df}=1.723, \mathrm{CFI}=1.00$, $\mathrm{GFI}=0.96, \mathrm{AGFI}=0.93, \mathrm{RMSEA}=0.043$ และ $\mathrm{SRMR}=0.006 . \mathrm{It}$ can be concluded that the structural formula model is suitable with the obvious data which can be described as follows:

(1) The chi-squared relation $\left(\chi^{2} / \mathrm{df}\right)$ is 1.723 ; the model is fit with the data because the chi-squared relation value is below 2.00 .

(2) The value of Comparative Fit Index (CFI) is 1.00, showing that the model is correlatively fit because CFI is above 0.90 .

(3) Absolute Fit Index: Goodness of Fit Index is equal to 0.96 and Adjusted Goodness of Fit Index is equal to 0.93,

showing that the model is fit to the data because GFI and AGFI values are in between 0 and 1, and the acceptable values of GFI and AGFI are above 0.90 .

(4) The value of Root Mean Square Error of Approximation (RMSEA) is 0.043; the model is fit to the data because RMSEA is below 0.05 or in between 0.05 and 0.08 . 
(5) The value of Standardized Root Mean Square Residual (SRMR) is 0.006; the model is fit to the data because SRMR is below 0.05 .

\section{B. Phrase II: The results from the influential pathway analysis}

The analysis of the casual influence of factors that affect the participation in caring of the volunteers (JOINT) is done in order to answer the study's doubt and hypothesis. Direct effects (DE), indirect effects (IE), and total effects (TE) are also introduced

It is found from the analysis of the factors' influence in the causal model of the factors that affect the volunteers' participation in caring the elderly (JOINT) with direct, indirect, and total influences that are symmetrical with the obvious data that such model is fit with the obvious data as shown in Figure 1 and Table II.

TABLE II. THE RESULTS OF INFLUENTIAL ANALYSIS OF FACTORS IN THE CASUAL MODELTHAT AFFECTS THE VOLUNTEERS' PARTICIPATION IN CARING (JOINT)

\begin{tabular}{ccccccc}
\hline \multirow{2}{*}{ Effect } & \multicolumn{3}{c}{ SA } & \multicolumn{5}{c}{ JOIN } \\
& & T & & & T & \\
\hline Cause & TE & IE & DE & TE & IE & DE \\
\hline \multirow{2}{*}{ MOT } & 0.99 & - & 0.99 & 1.00 & 0.32 & 0.68 \\
& $(0.04)$ & - & $(0.0$ & $(0.04)$ & $(0.25$ & $(0.25)$ \\
& 26.28 & - & $4)$ & 24.86 & ) & 2.73 \\
& & & 26.2 & & 1.30 & \\
\hline SAT & - & - & - & 0.32 & - & 0.32 \\
& - & - & - & $(0.25)$ & - & $(0.25)$ \\
& - & - & - & 1.30 & - & 1.30 \\
& & & & & & \\
\hline
\end{tabular}

Chi-Square $=117.8, \mathrm{df}=173, \mathrm{P}=0.00020, \mathrm{GFI}=0.96, \mathrm{AGFI}=0.93$, SRMR $=0.006$

As shown in Table II, the observable variables has a validity value at the perfect level which is in between 0.84 -

0.94 . The variables that has the highest validity value is the "promote" variable with 0.94 , the validity value of "interaction" is 0.91 , and the lowest validity value is the "motive" and "partner" variables with 0.84 .

The results observed from the correlation coefficients $\left(\mathrm{R}^{2}\right)$ of the structural formula of inside variables or dependent and sent variables which are the participation in caring of the volunteers (JOINT) $\left(R^{2}=0.99\right)$ and the volunteers' working satisfaction $(\mathrm{SAT})\left(\mathrm{R}^{2}=0.99\right)$ reveal that the predictor or casual factors of the motivation to become a volunteer (MOT) and the volunteers' working satisfaction (SAT) can be used to explain the influences in the participation in caring of the volunteer (JOINT), and in the volunteers' working satisfaction (SAT) with $99 \%$ probability.

When taking the direct and indirect influences impacting the volunteers' participation in the elderly caring (JOINT) into account, it is found that the influential variable that has a positive impact on the volunteers' participation in the elderly caring with the significant value observed at .01 is the

motivation of becoming a volunteer (MOT) with the influential impact at 0.68 .

Moreover, the variable of the motivation of becoming a volunteer has an indirect, positive impact on the volunteers' participation in caring (JOINT) with no statistical significance observed at .01 through the variable of the volunteers' working satisfaction (SAT) with the influential impact size at 0.32 .

The volunteers' working satisfaction (SAT) is the variable that has a direct, positive influence on the volunteers' participation in caring (JOINT) with no statistical significance observed at .01 with the influential impact size at 0.32 , and the motivation of becoming a volunteer (MOT) is also the variable that has a direct, positive influence on the volunteers' working satisfaction (SAT) with a statistical significance observed at .01 with the influential impact size at 0.99

\section{Phrase III: The results from a motive in becoming a volunteer \\ combined with different demographic factors on a level of participation}

The motive in becoming a volunteer is used as a controlled variable to facilitate comparison of the level of the care-for-theelderly-at-home volunteers' participation in the elderly care and different factors in an individual volunteer. After taking a process in examining the influence of the motive in becoming a volunteer from care-for-the-elderly-at-home volunteers on the

level of the participation with the use of demographic variables, it is found that the motive in working as a volunteer together with the factors of gender, monthly income, education level, marriage status, family size, other social service duties in society, frequency of training, practices of becoming a volunteer, and duration of volunteering directly influences on the level of the participation with a statistical significance level of .05. However, the factors of age and

occupation with a motive of working as a volunteer do not statistically impact the level of the participation in the elderly care. The first comparative analysis, thus, is done by analyzing covariates, using the motive of becoming a volunteer as a controlled variable. Then, the analysis of influences on the level of the participation is done without using the motive of becoming a volunteer as a controlled variable in this process.

The result reveals that a level of the participation in the elderly care is different with a statistical significance level of . 50if the factors of age, occupation, monthly income, family size, frequency of training after becoming a care-for-the-elderly-athome volunteer, duration of volunteering, subordinates and sections are taking into account. However, the factors of age and approach of becoming a volunteer does not significantly influence a level of participation in the elderly care. 
D. Phrase IV: The results from problems and obstacles to participation in the elderly care of the care-for-the-elderlyat-home can be divided into two aspects:

(1) Problems and obstacles in providing care for the elderly at home or in working together as a whole of care-for-theelderly-at-home volunteers mainly include failure to cooperate from the families of the elderly, obstacles to time management, traffic issues, lacks of necessary equipment and a number of volunteers, problems with working skills, and redundant works.

(2) Problems and obstacles involving with government sections, which negatively result in participating in the elderly care of the volunteers, include a lack of budget, support such as specific training, compensations, coordination, and opportunities for participating in the elderly care.

\section{DISCUSSION AND CONCLUSION}

The influences of all variables in the casual model affected the volunteers' participation in caring, the predictor or casual factors of the motivation of becoming a volunteer and the volunteers' working satisfaction can together be used to explain the influences of the volunteers' participation in the elderly care with $99 \%$ probability; the findings are in agree

with the study conducted by [1] and with the statement that factors which contribute to the participation are internal factors (goals, beliefs, habits and cultures), push factors

(expectations, obligations, forces) and external factors or support factors (opportunities, abilities, supports). Motivation

factors such as praising, receiving training, relationship with other volunteers and the feelings of a person who sacrifices are the important factors contributing to participation in a person. These findings are in accordance with the ones found from studies done by [2], [3], [4], [5], From the findings in this study, it is found that the volunteers' motivation is considered to be an internal factor and the satisfaction, especially, the satisfaction from government sectors in supporting for the volunteering activities such as the support from local public health care institutes or hospitals, village leaders, or the local department of social developing and security in a province. All two factors contribute to the participation of a public health volunteer in the elderly care at home.

When considering the direct and indirect influences affecting the volunteers' participation in the elderly care, it is found that the variable that has a direct and positive influence on the volunteers' participation in the elderly care at home is the motivation of becoming a volunteer with the influence size at 0.68 , especially in the internal motivation from the need of

environmental interaction, which is consistent with the study done by [6]. Since the volunteers consider that volunteering

activities is good and can help people in needs without anything in return, they feel more proud in themselves leading to eager to learn new things and using their knowledge to look after their family; the volunteering activities also make them to become known in their service area.

The motivation variable of becoming a volunteer has a direct, positive influence on the volunteers' working satisfaction with a statistical significance observed at 0.1 and the influence size at 0.99 ; this is fit with the findings reported in the works of [7] and [8], which explain that the volunteer will gain higher satisfaction when they have high motivation while the volunteers who has a little satisfaction are the ones who has low motivation. The motivation of the volunteers will also be affected by the satisfaction from supporting received from caring.

However, the motivation variable of becoming a volunteer affects indirectly and positively the volunteers' participation in the elderly care at home with no statistical significance observed at 0.1 through the sent variable of the volunteers' working satisfaction with the influence size at 0.32 . The reason for this to occur is that the satisfaction factors of the volunteers such as the satisfaction from received support, having authority, and relationship of the volunteers, all of which contribute to the participation. If there is no support

from government sectors, the volunteers are still working because of the heart of caring and loving volunteering with low participation, fitting in the findings that shows the relation between the motivation and the participation [9], [10], [11], and the findings of the volunteers satisfaction done by [12]. It can be concluded that the motivation affects the satisfaction, contributing to the participation of the volunteers.

Care-for-the-elderly-at-home volunteers whose monthly income is low, e.g. the volunteers who work in farming and gardening, tend to participate more in the elderly care than those whose monthly income is high because such volunteers have more time to donate to volunteering work.

Care-for-the-elderly-at-home volunteers whose family is small (only a father, a mother, and a child) participate in the elderly care more than those who does not have a family or live with only a child; this is because being alone or with a child makes the volunteer unable to devote time to volunteering works at all. On the other hand, care-for-the-

elderly-at-home volunteers who live with a spouse and a child tend to participate in the elderly care after a child care is finished. Some volunteers participate in elderly care because they want to provide their children an opportunity to work with government by doing volunteering works. Most care-forthe-elderly-at-home volunteers have their elderly parents whose house is near the volunteer's. Thus, the volunteers want to participate in the elderly care in order to utilize knowledge gained from volunteer working to help their parents who are sometimes in need.

Care-for-the-elderly-at-home volunteers who do not participate in any training prior to becoming a volunteer tend to participate 
more in the elderly care than those who join in trainings. This is due to the limit of budget from the government, resulting in no specific training in the elderly care for the volunteers. However,

all volunteers try to utilize their knowledge from other training courses from social health care to provide necessary care to the elderly. With enough support and budget to provide trainings to

the volunteers from government, satisfaction of the volunteers may be higher and affect a motive of becoming a volunteer in the future.

Another result from the findings also shows that care-forthe-elderly-at-home volunteers who are able to work in a long period of time are likely to participate in the elderly when compared to those who have a limit of time in working. This means that the volunteers who have been working for a long period of time and gain many experiences during the period of working are able to understand what the elderly really need and feel attached to the jobs. Coordination between volunteers and the Department of Local Administration becomes smooth, resulting in getting more support for such care. Undoubtedly, the

participation level in the elderly care will be positively influenced if there is enough support to help the experienced volunteers working.

Care-for-the-elderly-at-home volunteers who work for City Municipality, Town Municipality, Sub district Municipality, and Sub district Administrative Organizations are more likely to participate in the elderly care than those who work for other agencies (e.g. Ministry of Social Development and Human

Security). This result points out that the decentralization from government to the Department of Local Administration will provide an opportunity for all care-for-the-elderly-at-home volunteers to participate in creating a new campaign to support and encourage all care-for-the-elderly-at-home volunteers to participate in the elderly care with minimum support from Ministry of Social Development and Human Security.

Findings also reveal that care-for-the-elderly-at-home volunteers who live in a central part of Thailand are less likely to participate in the elderly care when compared to all the volunteers who live in other parts. It is possible that the

Ministry of Social Development and Human Security is still taking responsibility for volunteering works in providing care to the elderly, that volunteering works are being processed by the Department of Local Administration at the beginning step, or that the Department of Local Administration does not realize the importance of volunteering works provided by care- for-the-elderly volunteers as one of the best strategies to help providing social services to the elderly.

\section{ACKNOWLEDGMENT}

This work was partially supported by Sripatum University, Bangkok, Thailand.

\section{REFERENCES}

[1] Reeder, William W. Levels of Abstraction and Generality and Their Uses. Mimeographed, 8208.

[2] Suwannaboon, Kanookthong. Moral Values, Work Incentives and Social Supports as Promising Factors on Village Health Volunteers in Raying Province. M.A. (Community Psychology), the Department of Psychology and Consulting, Silpakorn University, 2552.

[3] Chaichana, Wutikrai. Factors Affecting People Decision to be The

Volunteer for Forest Fire Prevention and Control in Khun Mae Kuang National Reserved Forest, Amphoe Doisaket, Changwat Chiang Mai. B.S. (Forestry), Forest Resources Management Major, Kasertsart University,

[4] Mongkulkaeha, Amornmirt .Factors Affecting Motivation in Volunteering of Village Public Health Volunteers in Ban Niwed Subdistrict, Thawatchaburi, Roi Et. B.P.A. (Public Administration), Rajabhat Maha Sarakham University,2552

[5] Wongprathimaporn, Suwanna. Motivation Influencing on Volunteering of Village Public Health Volunteers from the Project of Encouragement in Active Village Public Health Volunteering in Chaiyaphum. Master of Public Health, Khonkaen University,2585.

[6] Hunter, Angela Tamara. Why Volunteer for The Environment? An Exploration of Environmental Volunteer Motivation, Satisfaction and Retention.. University Of Victoria (Canada), Proquest, UMI Dissertations Publishing, 2010. MR66804,2585.

[7] Gonzalez, K. Volunteer Motivations and Satisfaction in a Tutoring Program: Implications for Recruitment and Retention.. Pace University, Proquest, UMI Dissertations Publishing, 2009.3395651,2552.

[8] Proença, Teresa, F., Marisa R., Proença João F. Motivations which Influence Volunteers' Satisfaction.. Paper Presented at The 10th

International Conference of The International Society for Third Sector Research, Siena - Italy, 2012.

[9] Backman, K.F., Wicks, B., \& Silverberg, K.E. "Coproduction of Recreation Services. "Journal of Park and Recreation Administration. 15, 58-75,8220.

[10] Clary, E. G., Snyder, M., \& Stukas, A.A. "Volunteers' Motivations Finding from a National Survey." Nonprofit and Voluntary Sector Quarterly. 25 : 485-505,8226.

[11] Silverberg, K.E. "Understanding American Parks and Recreation Volunteers Utilizing a Functionalist Perspective." In Volunteering as Leisure, Leisure as Volunteering: An International Assessment.. 49-67. MA. : CABI Publishing,2554.

[12] Galindo-Kuhn, R. \& Guzley, R.M. "The Volunteer Satisfaction Index Construct Definition, Measurement, Development, and Validation.“ Journal of Social Service Research. 21,8 : 45-68, 2558. 